\title{
Presentism, Eternalism, and the Growing Block
}

\author{
KRISTIE MILLER
}

\section{A Brief Characterization}

Presentism, eternalism, and growing-blockism are theories or models of what the temporal and ontic structure of the world is, or could be. I shall set aside the question of whether whichever theory is true is necessarily true or only contingently true. Since defenders of each of these views at the very least think that they are competing views about the way our world is in fact, I focus discussion on this aspect of the dialectic.

Presentism, eternalism, and growing-blockism are, in part, theories about what exists. "Exists" is used in ordinary English in a number of ways. To understand what is at issue between these three views we need to understand what each view intends when it makes claims about what exists. Suppose I stand in my kitchen and utter the following three claims:
A. There is no Santa Claus.
B. There is no beer.
C. There are no dinosaurs.

When I utter (B) in my kitchen, what I say is true. That is because it is natural to understand me as claiming that there is no beer in my kitchen. Since there is beer at the local shop, the claim that there is no beer at all anywhere is false. That is, the claim "there is no beer" is false if we do not relativize the claim to some particular domain, like my kitchen, in which there is no beer.

When I utter (A) this is also true. ${ }^{1}$ But a natural reading of my utterance of (A) in my kitchen is not that that there is no Santa Claus in my kitchen, though that is true, but that there is no Santa Claus anywhere: no Santa simpliciter, as we put it. The difference between $(\mathrm{A})$ and $(\mathrm{B})$ is that a natural reading of $(\mathrm{B})$ tacitly restricts the domain

A Companion to the Philosophy of Time, First Edition. Edited by Heather Dyke and Adrian Bardon.

(C) 2013 John Wiley \& Sons, Inc. Published 2013 by John Wiley \& Sons, Inc. 
of quantification to be the domain of things in my kitchen, while (A) does not tacitly restrict the domain of quantification.

"Exists" is used restrictedly, when it is used to quantify over a restricted domain. It is used unrestrictedly when it is used to quantify over an unrestricted domain: the domain of everything. ${ }^{2}$ As we will see, eternalists and presentists disagree about the truth of (C): there are no dinosaurs. But both presentists and eternalists agree that if we read (C) as quantifying over a restricted domain, such as my kitchen, or the year 2011, then it is true. Their disagreement becomes apparent only if we understand their competing claims about what exists as claims about what exists unrestrictedly or simpliciter and therefore take them both to be making claims that quantify over an unrestricted domain.

With this in mind, very roughly presentism is a view that combines two core claims. The first is that only the present moment, and hence present objects and events, exist. If the present moment is July 252011 at midday, then I exist sitting here typing this paper, and Bill Clinton exists, and the live midday news exists. But dinosaurs do not exist, the event of Kennedy being shot does not exist, and the sentient robots that will be created in the future do not exist. Only what exists now, exists simpliciter. The second key presentist claim is that which moment is the present one changes from moment to moment. Dinosaurs are not present and hence do not exist. But the moment at which dinosaurs did exist was once present. The moment at which sentient robots are created will at some time become present.

Thus presentism combines an ontological thesis with a dynamical thesis.

Presentist Ontological Thesis (POT): Only the present moment exists.

Dynamical Thesis (DT): The present moves: which moment is the present moment changes.

Thus a presentist world is one that dynamically changes over time: the totality of events that exist changes as time passes, so that a different set of events comes into existence as each new present moment comes into existence, and those events then pass out of existence as that moment ceases to be the present moment. (Bigelow 1996; Bourne 2006; Crisp 2005; Markosian 2004; Oaklander 2002; and Zimmerman 2008). ${ }^{3}$

Eternalists, by contrast, deny both POT and DT. Eternalists hold that past, present and future moments (and hence past, present and future events and objects) exist. Eternalists view objects that exist (and events that occur) at other times as being analogous to objects that exist (and events that occur) at other places. Just as Singapore exists, despite not existing here in Sydney, so too dinosaurs exist, despite not existing now in 2011. One way to think about this is to picture an eternalist world as being one in which all events, past, present and future, are located in a four-dimensional block of spacetime. Events on the block are ordered by being earlier than, later than, or simultaneous with, one another: the event of the dinosaurs living is earlier than the event of Kennedy being shot which is earlier than the event of the sentient robots being created. ${ }^{4}$ Those relations are unchanging. If the dinosaurs are located earlier than Kennedy being shot, then at all times it will be true that the dinosaurs are located earlier than Kennedy being shot. 
Thus eternalists endorse the following pair of theses:

Eternalist Ontological Thesis (EOT): Past, present, and future times and events exist.

Static Thesis (ST): The present does not move: which moment is the present moment does not change.

A quick clarification: the moving spotlight view combines the eternalist's ontological thesis with the presentist's dynamical thesis to yield a view according to which past, present and future events exist, but there is an objective property of presentness that moves through the block progressively "lighting up" different times (Skow 2009). Sometimes this is thought of as a variant on eternalism. Here I use "eternalism" to pick out standard eternalism, which rejects the dynamical thesis.

Eternalists, then, hold that the world as a whole is static in two senses: which events exist does not change, and there is no sense in which the present moves. (Le Poidevin 1991; Peterson and Silberstein 2010; Quine 1960, 1963; Smart 1968). The moving spotlight view endorses the former conjunct but not the latter. Presentists and growingblock theorists deny both conjuncts.

Eternalists accept what is known as the B-theory of time. This is the view that the world is a static block of events ordered by the earlier than, later than, and simultaneous with, relations. Which moment is present does not change, because the phrases "the present" and "now" do not pick out a metaphysically special feature of the world. Presentness is not a property that one time has and the others lack, and which can move around. Rather, "now" and "present" are, roughly, indexical terms - terms that pick out the time at which one utters them (Dyke 2002a; Mellor 1981,). Every time is present or now to the persons located at that time.

The B-theory contrasts with the A-theory, according to which in addition to relations of earlier than, later than, and simultaneous with, there exist properties of presentness, pastness and futurity and these properties are had by different sets of events at different times (Craig 2000; Ludlow 1999; Prior 1967; Smith and Oaklander 1994). These properties need not be intrinsic or irreducible properties of times, they might be extrinsic or relational properties. For instance, the presentist might say that the present moment has the property of presentness in virtue of being the only moment that exists. Then she might construe pastness and futurity as properties only had by ersatz times related earlier than or later than the ersatz time that represents the current moment (Bourne 2006). Or she might hold that such properties are never instantiated in a presentist world.

Presentists endorse the A-theory, since they hold that it is a genuine feature of a presentist world which moment is present, and that this fact changes over time so that different moments are present at different times. To say that a view accepts the A-theory is really to say that it endorses the dynamical thesis, and to say that it endorses the B-theory is to say that it rejects the dynamical thesis.

Finally, growing-blockism is, intuitively, a view that falls somewhere between presentism and eternalism. On the one hand, it rejects the ontological theses of both eternalism and presentism. Like the eternalist, the growing-blockist holds that past 


\section{KRISTIE MILLER}

moments exist and like the presentist she holds that future moments do not exist (Forrest 2004, 2006; Tooley 1997). Her view combines the following two theses:

Growing Block Ontological Thesis (GBOT): Past and present moments and events exist, but future moments and events do not exist.

Dynamical Thesis (DT): The present moves: which moment is the present moment changes.

According to growing-blockism, reality is a growing block. Every event on the block is located in the past, except for those events that occur on the three-dimensional slice at the very end of the growing edge of the block. Events on that slice are in the objective present. Once the block grows and a new slice is added, events that were at the very edge of the block cease to be in the present and become part of the objective past. As time passes the present moves as progressively more "slices" of reality are added to the sum total of what exists. When new moments come into existence and become the objective present, earlier moments become part of the objective past.

\section{Definitional Woes}

In introducing these views, I often used the phrase "very roughly." I did so because it is contentious exactly how each view should be defined. First, there is considerable dispute over whether there is a non-trivial way of delineating presentism and eternalism.

Suppose a world can be represented as a four-dimensional manifold of events that include all of the events that did, do and will exist (think of this as a four-dimensional block of events). Representing a world this way does not commit us to holding that all of the events thereby represented exist: the question of which exists can remain an open question. The four-dimensional block can be divided into three-dimensional slices. Slicing the manifold into three-dimensional slices is known as foliating spacetime, and each of the slices is known as a hyper-plane or a time-slice (Minkowski 1908). Each of these slices is, very roughly, a slice of spacetime such that all of the events on the slice are simultaneous with one another relative to some frame of reference. There are many different ways to foliate a four-dimensional spacetime, just as there are many different ways of slicing up a three-dimensional hunk of Spam. If your Spam is a cube, and you cut each slice perpendicular to the table, you get a bunch of square slices. If you slice on an angle, you get rectangular slices. Which bit of Spam is on which slice depends on how (that is, at which angle) you slice your Spam.

Eternalism is the view that all of the events represented on the four-dimensional manifold exist. Presentism is usually the view that there is one correct way of foliating the manifold, and that just one hyper-plane of that foliation represents the one time, and set of events at that time, that exist. ${ }^{6}$ But while presentists hold that a single hyper-plane exists, they also hold that, other hyper-planes did exist, and still further hyper-planes will exist. So for the presentist, the total set of hyper-planes that did, does or will exist is just the total set of hyper-planes that for the eternalist does exist. 
This has led some to suggest that presentists and eternalists are using "exists" in a different way and are therefore not really disagreeing but are talking past one another (Hirsch 2002). The idea is that presentists and eternalists agree about the totality of moments that do, did or will exist. But eternalists use "exists" to quantify over present, past and future events, and presentists refuse to use "exists" to quantify over past and future events. Thus the presentist speaks truly when she says that only present moments exist, and the eternalist speaks truly when she says that past and future moments exist.

What does this claim amount to? One possibility is that presentists are tacitly restricting the domain of quantification to the present moment, while eternalists are not restricting the domain of quantification. Then both parties mean the same thing by "exists" but one is tacitly restricting the domain over which the term ranges. Given this restriction, the presentist speaks truly when she says that only present events exist and eternalists speak truly when they say that past and future moments exist. The disputants do not disagree about what exists unrestrictedly.

But presentists explicitly deny that they are tacitly restricting the domain of quantification, and eternalists generally take them at their word.

Another way to interpret the claim that the two parties are talking past one another is that the domains of quantification are the same, but "exists" means something different in the mouths of each party. It is controversial whether "exists" can have different meanings and whether if it can, it actually does have different meanings in the mouths of presentists and eternalists (Sider 1999, 2009). Even if it can and does, it is noteworthy both that neither eternalists nor presentists accept that this is an accurate diagnosis of the dialectic; nor does a stipulation about what "exists" means seem to result in an evaporation of the dispute between the parties. At best we can say that if the parties really are talking past one another, their quantification over different domains or their use of terms with different meanings is very resistant to being recognized as such.

While presentists and eternalists at the coalface typically resist the suggestion that they are talking past one another, there is a related suggestion that any way of interpreting "exists" will either render presentism equivalent to eternalism, or render it obviously false. There are only two interpretations of the presentists' claim that only present events exist. The first is that only present things exist now. The second is that only present things exist, existed, or will exist. But the former is trivially true and entirely consistent with eternalism. Everyone agrees that a single hyper-plane exists now, just as everyone agrees that a single spatial location exists here. The latter is obviously false, since it entails that all that ever exists is a single hyper-plane (Crisp 2004; Ludlow 2004; Meyer 2005, 2011).

Perhaps if the presentist appeals to the dynamical thesis she can avoid falling on to one or other of these horns. To do so we must revisit "exists" and answer the question of whether the unrestricted quantifier is tensed or tenseless (Lewis 2004; Meyer 2011; Sider 1999, 2006). On a tenseless view, the quantifiers range over the same domain of objects at all times: the domain of the objects that did, do and will exist. On a tensed view, the quantifiers range over different domains at different times, so that at $t$, the quantifiers range only over those objects that exist at $t$ and at $t^{*}$ they range only over the objects that exist at $t^{*}$.

Suppose "exists" is tenseless. Then it is hard to make sense of the idea that the present moves, and that different hyper-planes come into and go out of existence. For the set 
of hyper-planes that did, does and will exist, according to the presentist, is the total set of hyper-planes to which the eternalist is committed. Again, presentism fails to be distinguishable from eternalism.

Suppose instead "exists" is tensed. Then at each $t$, the quantifiers range over the domain of objects that exist at $t$. Notice a potential ambiguity in this last claim. The quantifiers range of the domain of objects that exist at $t$. The obvious and most usual interpretation of this is that the domain of objects that exist at $t$, includes the objects located (or partially located) on the $t$-slice. Then at each $t$, it will be true that the set of $t$-objects (the objects that exist on the $t$-slice) exists and no other objects exist. But again we fail to distinguish presentism from eternalism, since the eternalist agrees that given a tensed quantifier, at each time $t$ all that exists are the $t$-objects. Again, we fail to find any dynamism.

There is another alternative. Suppose that the domain of objects that exist at $t$ is the domain of objects that exist relative to $t$. That is, it is the domain of objects that exist when $t$ is the present moment. To see the difference consider a growing-block world. In such a world there is a difference between the set of objects that are located on the $t$ slice, and the set of objects that exist on some slice or other when the $t$-slice is the objective present. In general, given dynamism, we want to say that relative to different present moments, different total sets of events exist. In particular, presentists want to say that when time $t$ is the present moment, only the events at $t$ exist and when $t^{*}$ is the present moment, only the events at $t^{*}$ exist, and that at different times, different times are the present moment. Given growing-blockism, we want to say that when $t$ is the present moment set $S$ of events exists, and when $t+$ (a later moment) is the present moment, set $S+$ of events exists, and $S$ is a proper subset of $S+$. But relative to what are different times present? Here, I think, an appeal to a second temporal dimension, often known either as meta-time or hyper-time, is needed. Meta-time is, roughly, supposed to be a temporal dimension very much like the temporal dimension with which we are familiar, but distinct from it in the way that the third spatial dimension is similar to the two other spatial dimensions, but is distinct from them. If there is meta-time in our world, then ours is a five-dimensional world insofar as it has three spatial dimensions and two temporal ones (though if presentism is true, nothing is extended along at least one of the temporal dimensions).

If we posit meta-time, we can maintain that different times are present relative to different meta-times. Let us suppose that tensed quantifiers range over the meta-times. At meta-time $M_{1}$, the tensed quantifier ranges over all the events that exist at meta-time $M_{1}$. What exists at any particular meta-time? Ordinary times. If dynamism is true, this is because when the tensed quantifier ranges over different meta-times, it thereby ranges over a different set of ordinary times. In a growing-block world, a set of ordinary times, $t_{1} \ldots t_{n}$ exists when the tensed quantifier ranges over $M_{1}$. A different set of ordinary times exists when the tensed quantifier ranges over $M_{2}$. The same is true in a presentist world, except that the different sets of ordinary times that exist when the tensed quantifier ranges over different meta-times are singleton sets that contain a single time as a member.

While there is nothing incoherent in introducing the idea of meta-time, those who endorse the dynamical thesis generally reject the notion that they are thereby commit- 
ted to an additional temporal dimension. It is easy to see why they resist such a move. First, accepting a second temporal dimension might result in a vicious regress of dimensions, at least if the meta-temporal dimension is itself dynamical. For then a further temporal dimension will be needed in order to explicate how the present moment in meta-time moves. The regress is avoided if meta-time is B-theoretic. But then one danger is that presentism ultimately collapses into a kind of five-dimensional eternalism. Another danger is that positing an extra temporal dimension is ontologically excessive, and falls foul of Ockhamist and similar principles - that is, principles according to which we ought not posit any things in our ontology than are strictly necessary to explain the relevant phenomenon.

Another way to get a handle on the problem presented by the dynamical thesis is to focus on the role of tense in theories that endorse that thesis. Such theories take seriously the idea that there is an objective present and that we represent objective temporal passage in terms of moments passing from being future, to being present, to being past. The properties of presentness, pastness and futurity are what McTaggart (1908) famously called A-properties and which, he went on to argue, are inconsistent. No event can be present, past and future. Yet on a dynamical model every event must have all three designations. This apparent inconsistency led McTaggart to reject the reality of time, since he held that without A-properties there is no time, but necessarily there are no such properties (see Bigelow, "The Emergence of a New Family of Theories of Time", this volume Chapter 10).

The standard move on behalf of dynamical theories is to point out that no event need have all three properties at the same time (Lowe 1992, 2011). But many eternalists think this move fails, and the A-theory is incoherent (Dyke 2001, 2002b; see also Thomson 2001 for discussion of these issues). One possibility is that we understand the idea that the A-properties are had at different times, in terms of a second temporal dimension. How is it that an event $E$ goes from being future, to being present, to being past? By $E$ being past, present and future relative to different meta-times. McTaggart considers this possibility, but since he supposes the A-series to be essential to temporality, he must suppose that any meta-temporal dimension is itself A-theoretic. Thus this move cannot succeed, for him, since we will necessarily end up with an infinite regress of meta-temporal dimensions.

To sum up then: there is a general sense that we know what defenders of presentism, eternalism and the growing-block theory are arguing about. What is controversial is whether there are three distinct models that are not only internally consistent, but such that each captures the view that its defenders intend. There are three core worries. First, whether presentism and eternalism can adequately be distinguished or whether the two parties are talking past each other either by using "exists" with different meaning, or by quantifying over different domains. Second, whether once we focus on the possible and plausible domains of quantification for "exists," it turns out that for each, presentism is either trivially true or obviously false. Third, whether the only way adequately to make sense of the dynamical thesis of growing-blockism and presentism is to appeal to a second meta-temporal dimension and if so, the extent to which that is a cost. Since these definitional issues could just as easily be expressed as objections, their consideration nicely brings us to some more general objections to each of the three views. 


\section{Objections and Problems: Presentism}

\subsection{Tensions With Our Best Science}

A frequent objection levelled at presentism is that it is inconsistent with, or at least in tension with, our best science: in particular, with the theory of special relativity (LePoidevin 1991; Price 1997; Putnam 1967; Savitt 2000; Wüthrich 2011). Recall in the previous section we supposed that we could represent worlds as four-dimensional manifolds that can be "sliced" into three-dimensional hyper-planes, and that there are various different ways of slicing a world depending on the "angle" of the slice (recall our block of Spam).

Now suppose that the world that we are representing is our world. According to the special theory of relativity (STR) there is no uniquely correct way to foliate spacetime into hyper-planes. Depending on the speed at which one moves - that is, depending on one's frame of reference - spacetime will foliate differently and different sets of events will be simultaneous. Thus two persons, say John and Bert, occupying two different frames of reference, may disagree about whether some set of events occurs at the same time, or at different times, and there is no fact of the matter as to which of them is right. This is because STR famously holds that simultaneity is relative: there is no privileged reference frame - no one correct reference frame from which to judge simultaneity and hence no privileged set of events is "really" or "absolutely" simultaneous.

This presents little difficulty for the eternalist, since she can think of each set of perpendicular slices as representing one way of ordering events on the block, relative to one frame of reference. Other sets of slices sliced at a different angle represent other ways of ordering events on the block, relative to other frames of reference.

Matters are not so straightforward for the presentist. For suppose that John and Bert co-exist, that is, each judges the other to be simultaneous with himself. Suppose that according to Bert, Mary co-exists with Bert. Suppose existence is transitive - if $x$ co-exists with $y$, and $y$ co-exists with $z$, then $x$ co-exists with $z$. Then it follows that John co-exists with Mary. But it is consistent with all that we have said that from John's frame of reference, Mary does not co-exist with John but instead Mary is located earlier, or later, than John. So if John is committed to Mary's existence, then he is committed to the existence of objects that are not, relative to his frame of reference, in the present. Since we can set up long chains of observers located in different frames of reference, we can derive the conclusion that John ought to be committed to the existence of objects he takes to be very distantly located in the past or future, and likewise for all the other observers in the chain (Putnam 1967).

This argument appears to threaten both the ontological and dynamical claims of presentism (and also growing-blockism). We might interpret the claim that no frame is privileged as the idea that all of the hyper-planes in the representation of our world are on an equal metaphysical footing. Since no frame is privileged, no single hyper-plane in the representation can be picked out from the set as being the unique plane that represents an actually existing hyper-plane and no set of events represented can be selected as all and only the events that are truly simultaneous. Therefore we should accept that all of the hyper-planes exist, and therefore that non-present events exist. 
The dynamical thesis is also threatened. It entails that there is a moving present, and therefore that there is something privileged about one of the many hyper-planes represented by the four-dimensional manifold. It requires that at any time one of the hyperplanes is the objectively present one and the other hyper-planes are not, and that at each subsequent time a different hyper-plane is the objective present.

For the presentist these two worries coincide, since for her the objective presentness of a unique hyper-plane consists in that hyper-plane being the only one that exists. An analogous worry arises from the growing-block theorist, since for her the presentness of a particular hyper-plane is grounded in that plane's being at the very end of the growing block: it is grounded in the slice or hyper-plane being such that there is a hyper-plane that exists earlier than it, but there is no hyper-plane that exists later than it. But if there is no way to make sense of the ontological thesis of the growing-block theory because one must be committed to the existence of all of the hyper-planes, then there is likewise no way to make sense of the idea of an objectively privileged hyper-plane that is the present and no way to make sense of the dynamical thesis.

Though this is a powerful argument, it does not show that presentism or the growingblock theory are inconsistent with STR. According to STR there is no privileged hyperplane. But the presentist and growing-blockist are free to reject the idea that this entails that all of the hyper-planes in our representation of the four-dimensional manifold are metaphysically on a par and hence that each corresponds to an existing hyper-plane (Bourne 2006). They can instead contend that STR tells us that there is no physically privileged hyper-plane: that is, it is no part of our best theories in the physical sciences that any single hyper-plane is privileged. Empirically, if you will, all planes are equal: no experiment could reveal one hyper-plane to be privileged. But being physically or empirically on a par is not the same as being metaphysically on a par. The dynamical thesis says that there is a metaphysically privileged hyper-plane, but does not suggest that we have or could have any access to which hyper-plane is privileged and thus does not entail that a metaphysically privileged hyper-plane is thereby physically or empirically privileged. Thus what STR tells us is that it is in principle impossible to determine which plane is the metaphysically privileged one. But it does not tell us that no plane is in fact metaphysically privileged.

This response renders STR consistent with the dynamical thesis of presentism and growing-blockism, but it comes with costs. The dynamical thesis is in part motivated by the thought that it seems to us as though time flows, and as though the present moment is importantly different to other moments. Presentists and growing-blockists take this phenomenology seriously, attributing it to the fact that the world really is one in which times flows and the present is importantly different to other moments. But this contention is in striking tension with the claim that although there is a privileged hyper-plane, we could never know which it is, since its being metaphysically privileged does not entail its also being empirically or physically privileged (Prosser 2000, 2007). But if there is no way to detect which plane is privileged and its being metaphysically privileged makes no empirical difference in the world, then it is hard to see how the fact that a plane is metaphysically privileged could ground our temporal phenomenology. How can that which is empirically epiphenomenal be the explanation for the way the world seems to us? But if a plane's being metaphysically privileged is not what grounds 
our temporal phenomenology, then what motivation is there for positing the existence of a privileged plane?

The presentist and growing-block theorist can also meet the distinct challenge that STR appears to offer to their respective ontological theses. The problem offered by STR is essentially that since different objects co-exist relative to different frames, and since co-existence is transitive, we should admit into existence events that are, from our frame of reference, non-present. To get this argument off the ground one must suppose that co-existence is transitive. But that can be denied. Instead it can be argued that what we have learned from STR is that all talk should be frame-relativized, and therefore that talk of existence and co-existence ought to be frame-relativized. We should resist the claim that co-existence across different frames is transitive.

Again there are costs to this move. The idea that existence itself is not transitive is counterintuitive. It is, after all, the idea that although $X$ exists relative to Peter, and Peter and Bert exist relative to one another, nevertheless $X$ does not exist relative to Bert. Since presentism prides itself on being a folk-friendly view, rejecting what appears to be a very folk-friendly view about existence is costly. Still, this cost is less than the one involved in holding that although there is a privileged hyper-plane, its being privileged makes no empirical difference. One can point out that there are many counterintuitive consequences to STR, and the intransitivity of co-existence is one of these. It is more damaging to those who accept the dynamical thesis that it turn out that one of the core motivations for accepting dynamism - our temporal phenomenology - is undermined by conceding that given STR, which hyper-plane is metaphysically privileged is empirically undetectable (Savitt 2000).

There is another cluster of responses to the tension between STR and dynamical theories, which rejects STR as the true (or approximately true) physical theory. Most such responses do not reject outright the role of physics in providing an account of the nature of our world: they are less revisionary than that. Instead, they suggest that there are other theories, often known as neo-Lorentzian theories, that are empirically equivalent to STR and which are not a threat to dynamism. I will not discuss these responses here.

\subsection{Making Sense of Past-Tensed Claims}

Another challenge facing the presentist lies in making sense of past-tensed statements. Whether we think dinosaurs exist or not, most of us think that claims like "dinosaurs did exist" and "some dinosaurs were large" are true. But what makes those claims true? For the eternalist the answer is easy, it is that there is a region of spacetime located earlier than our current region, and large dinosaurs exist in that region.

One expects that claims about what is the case are made true by states of the world. If "penguins are black and white" is true, it is because of the way the world is with respect to penguins. Since presentists hold that there are no past or future events, those events cannot ground the truth of past or future-tensed statements. Instead, the present state of the world must ground the truth of past- (and future-) tensed statements if anything does. How can the present moment ground truths about the past? That depends on which presentist you ask. Ersatz presentists hold that other times are a bit 
like other possible worlds. Just as ersatz worlds are abstract objects that exist in our world and represent the ways things could have been but aren't, so, too, ersatz times are abstract objects that exist in the present moment and represent the ways things were in the past but are no more. The crucial difference between the two cases is that the ersatz presentist must also introduce an ordering relation on the ersatz times which is analogous to an earlier and later-than ordering so that she can say that ersatz time $t$ is later than ersatz time $t^{*}$ (Bourne 2006).

Then, according to the ersatz presentist, "dinosaurs were large" is true just in case there is an ersatz time $t_{n}$ that represents our current moment, and there is an ersatz time $t_{m}$ which is earlier than $t_{n}$, and $t_{n}$ represents there being large dinosaurs. The important feature of ersatz presentism for current purposes is that abstract objects ground past or future-tensed statements (Bourne 2006; Crisp 2007).

Other presentists ground past-tensed truths by appealing to tensed properties that are instantiated in or by the present moment. For instance, suppose it is true that Mary was ten, though Mary is now twenty. The presentist can ground the truth of "Mary is twenty" in currently existing Mary's having the property of being twenty, and can ground the truth of "Mary was ten" in currently existing Mary's having the tensed property of having been ten. That won't work for all past-tensed statements, since there are no dinosaurs around now, to have, for instance, the property of having been large in the past. One possibility is that there is just one set of fundamental particles that have existed from the beginning of the universe. Those particles exist in the present moment, and certain sets of those particles have tensed properties. So there is a set of particles that has the tensed property "having once composed a dinosaur" and that is what makes it true that at least one dinosaur existed in the past. But the presentist does not need such a complex account, she can hold that the present moment itself has past-tensed properties that ground the truth of past-tensed claims (Bigelow 1996). The present moment has the property, for instance, of being such that dinosaurs did exist.

Alternatively, suppose determinism is true, that is, the laws of nature plus a complete specification of the particular matters of fact at a time, completely determine the way the world is at every other time. Then the presentist might hold that the current state of the world, plus the laws of nature, determine the way the world was, and this grounds past-tensed truths. Unfortunately, if determinism is false - if the laws of nature are chancy or probabilistic - then when we combine them with the particular matters of fact at a time they will not uniquely determine the way the world was, (or will be) at every other time. Instead there will be a range of possible past states of the world that are consistent with the probabilistic laws and the current state of the world. So there will be some past-tensed statements that are neither true nor false. That seems counterintuitive in the extreme. It may be impossible to know whether Fred the dinosaur killed two or three herbivorous dinosaurs on a particular day in the past, but surely there is a fact of the matter.

It is also worth noticing that grounding truths in the laws of nature can only succeed if the presentist rejects certain metaphysical conceptions of those laws. If the laws of nature are Humean - if the laws are the best systematizations of the total distributions of matters of fact - then it is hard to see how we could ground past-tensed truths by appealing to those laws. For we cannot extract Humean laws from the present 
moment: we need access to the entire mosaic of facts in order to determine the appropriate systematization of those facts. If presentism is true, then we need access to past and future-tensed facts about what did and will happen since the laws are the best systematization on this totality of facts. But if we appeal to past and future-tensed facts to determine the laws, we cannot then use the laws to ground the truth of past-tensed statements. So the presentist must reject Humean-style accounts of the laws of nature in favor of something more like Armstrong's view of laws as universals related by nomic necessitation.

These are just a few of the myriad options on the market for grounding past-tensed claims in the present moment. These approaches all do the job, with varying degrees of success, with the possible exception of the appeal to the laws of nature which, if the laws are not deterministic, leaves some claims about the past as neither true nor false. But the general worry with all of these strategies is that they locate the truthmaker for past-tensed statements in the wrong sort of place. They get the right claims to come out true, but they do so in the wrong kind of way (Caplan and Sanson 2011; Keller 2004). In the present, the claim "penguins are black and white" is grounded by fleshand-blood penguins and the color that they are. But the similar claim "penguins were black and white" is not grounded by anything remotely penguin-like. It is grounded by an abstract object, or by a sui generis tensed property of the present moment, or by the laws of nature and the particular current matters of fact. But many suppose that none of these seem like the right kinds of things to ground that claim, because it ought to be grounded in something very much like what grounds the present-tensed claim that "penguins are black and white". Here we have a clash of intuitions. Since presentists think that there are no past objects, perhaps they quite rightly think that what grounds past-tensed claims must be radically different to what grounds present-tensed claims (Button 2006, 2007; Crisp 2007; Kierland 2011; Tallant 2009). The objector's worry is then perhaps best thought of not as the concern that what grounds past-tensed claims is different in kind to what grounds present-tensed claims, but rather, that the difference is the wrong kind of difference because what it is that grounds past-tensed claims turns out to be the wrong kind of thing to plausibly do the job.

\section{Objections and Problems: Eternalism}

\subsection{Free Will and Fatalism}

Eternalism is, inter alia, the view that past, present and future events exist. If there will be sentient robots, then there are sentient robots. Just not around here. If there will be nuclear war with the sentient robots, there is nuclear war with the sentient robots. Just not around here. That has led most philosophers to conclude that in an eternalist world, the future is fixed: for any future-tensed claim uttered at $t$, that claim is either true at $t$, or false at $t$, and it is determinate, at $t$, which of these truth values it has. ${ }^{7}$ If I now utter the claim "sentient robots will take over the world" that claim is now either true or false, because there is either a region of spacetime in the future in which there are sentient robots taking over the world, or there is no such region of spacetime. The fixity of the future might lead one to feel a little queasy. If the facts about what will happen 
are fixed, then what room is there left for free will, and shouldn't we all just be fatalists?

This seems to me to be misplaced as an objection primarily to eternalism. Notice that this objection, or one like it, arguably also cuts against presentism if it cuts against eternalism. How so? Nothing about presentism per se guarantees that in a presentist world the future is not fixed. The presentist is committed to the claim that future objects and events do not exist. So there are no sentient robots. But there are also no dinosaurs. As we saw in the previous section, presentists must come up with a way of grounding the truth of past-tensed claims. But since the past and the future are ontologically on a par, it is prima facie plausible that whatever apparatus the presentist uses to ground past-tensed statements will (or at least could) also ground future-tensed statements. This is very easy to see if one grounds past-tensed statements in the totality of matters of fact in the present plus the laws of nature. For the actual laws of nature are symmetrical, and if they are deterministic then they completely determine not only what did happen in the past, but also what will happen in the future. Thus for every pasttensed or future-tensed claim, that claim is either true or false and determinately so. Likewise, while one clearly could suppose that the world has sui generis past-tensed properties that serve as truthmakers for past-tensed statements, but does not have sui generis future-tensed properties that serve as truthmakers for future-tensed statements, it is not clear in virtue of what a world would be like that. Introducing such a difference would seem to be ad hoc without an independent explanation for why the former, but not the latter, exist. And that explanation had better not be that the former exist because the past did exist, while the future does not yet exist.

So the presentist is not, despite appearances, in an obviously better position to deny that the future is fixed if she also wants to maintain that the past is fixed. This is unsurprising: the eternalist and the presentist treat the future and the past on an ontological par. That makes it difficult to hold that there is fixity in the past, but not in the future. In this respect both the eternalist and presentist differ from the growing-blockist, who has the resources to explain how the past can be fixed but the future not: for the past exists and grounds the truth of past-tensed statements, but the future does not exist, and hence fails to ground any truths about future-tensed statements. ${ }^{8}$

On the safe assumption that the presentist is committed to a fixed past, and hence also, by this reasoning, to a fixed future, does this mean that both eternalists and presentists (but perhaps not growing-blockists) should be concerned about free will? There are reasons to think not. Suppose that the future is fixed. Future-tensed statements are, now, either true, or they are false. Suppose it is true that there will be a war with sentient robots. In a sense we cannot do anything about that whatever we in fact do, the war with the robots will come to pass. But that does not mean that what you or I choose to do makes no difference to the way the world turns out, or that somehow our choices are constrained in a deleterious manner. It is consistent with it being the case that there will be a war with sentient robots, that the reason there is such a war is because of what you and I do now. Indeed, one would expect that the reason there is such a war, is in part because we build such robots. We make certain choices, and these choices have a causal impact on the way the world is. These choices, in effect, bring it about that there is a war with the robots in the future. Moreover, it is consistent with the fact that there will be such a war, that had we all made different choices, there would 
have been no war, and the facts about the future would have been different. The future would equally have been fixed, but the fixed facts would have been other than they are. From the fact that whatever choices we in fact make, these lead to a war with the robots, it does not follow that had we made different choices, there would nevertheless have been a war with the robots.

Perhaps there are quite general reasons to worry about whether you and I have free will in some appropriately meaty sense. But future-tensed statements now having determinate truth-values does not give us any additional reason to worry about free will.

\subsection{Where is Flow and Change?}

Both presentism and the growing-block theory have an inbuilt account of temporal flow and change. Both are dynamical models in which the totality of the world changes over time. For the presentist, temporal flow is modelled by the coming into and passing out of existence of progressive presents. For the growing-blockist, temporal flow is modelled by the coming into existence of new moments, each of which is the present moment until the next one comes into existence, at which point that moment passes into the objective past. Both have a ready answer to the question of why it seems to us as though time flows and as though our world is constantly changing: because it does. Eternalism, on the other hand, is a static view that rejects temporal flow. Since it certainly seems to many that there is temporal flow and change, this is a cost to eternalism. At the least, the eternalist owes us an account of why it should seem that there are such features in the world when there are not. (For eternalist explanations of why we seem to experience temporal flow see Dyke and Maclaurin, "Evolutionary Explanations of Temporal Experience," Chapter 30 of this volume, and Dainton, "The Perception of Time," Chapter 23 of this volume; for eternalist accounts of change see Goswick, "Change and Identity Over Time," Chapter 22 of this volume.)

There is no shortage of suggestions for eternalist accounts of why we have the phenomenology we do. It remains an open question whether any of these accounts are convincing.

\section{Objections and Problems: The Growing Block}

\subsection{Epistemic Problems}

As we saw in Section 3, growing-blockism faces many of the same problems as the presentism when it comes to the theory of special relativity. I will not revisit those worries here. Instead, I focus on a cluster of objections that target growing-blockism but not presentism. ${ }^{9}$

Suppose that our world is a growing block. Our phenomenology as of temporal flow, and of the present having a particular quality that the past and future lack, are supposed to be explained by the gradual accretion of new time-slices, each of which is the objectively present moment when it comes into existence, and thereafter passes into the objective past. Consider Julius Caesar at the moment at which he crosses the 
Rubicon. There was a time when Caesar was in the objective present. Thereafter, he has been in the objective past. Suppose that in $60 \mathrm{BC}$, when Caesar is having a chat to Cicero about Pompey, Cicero asks Caesar whether either or both or them are located in the present. There is a moment - a durationless instant - at which, were Caesar to (very rapidly) answer "yes", he would speak the truth: namely when the relevant threedimensional slice upon which he and Cicero are located, is at the very edge of the block. Thereafter, Caesar would be wrong to answer "yes". Cicero then puts it to Caesar that since there are either an infinite number (if time is continuous) or a very large finite number (if time is discrete) of locations in the four-dimensional block that are in the objective past, and only one instant that is in the objective present, that he and Caesar ought to think it far more probable that each of them is in the objective past (Bourne 2002; Braddon-Mitchell 2004; Merricks 2006).

The problem to which Cicero alludes is that in a growing-block world, it does not seem possible to determine whether one is located in the objective present or the objective past, and given this, one should conclude that almost certainly one is in the objective past. The worry is twofold. First, there is the epistemic worry that none of us can know whether we are located in the present or not. The second is that if each of us has more reason to think we are located in the objective past than in the objective present, then the explanation for our temporal phenomenology cannot be that we are located in the objective present. At least, the explanation for my temporal phenomenology cannot be my location in the objective present on the assumption that whatever my phenomenology is like when slice $S$ comes into existence with (some slice of) me as a part of it, that phenomenology remains the same regardless of whether there are slices that occur earlier than $S$ but not later, or whether there are slices that exist both earlier and later than $S$.

Defenders of the growing block have responded to the epistemic challenge by denying this last claim (Forrest 2004, 2006; Merricks 2006). In essence, this is to deny that my phenomenology at $t$ supervenes on the way the world is at $t$ or at and before $t$. The suggestion is that it is necessary for the existence of phenomenology at a time $t$, that $t$ is the objectively present slice. Thus insofar as you and I know that we have phenomenology, we thereby know that we are in the objective present. This response is sometimes known as the dead past view, since it entails that all persons located in the objective past lack phenomenology, though those persons did have phenomenology when they were located in the objective present. What is perplexing about this view is, first, that it entails that the having of phenomenology depends not just on the way the world is at $t$, and perhaps was before $t$, but on whether there exists a slice that is later than $t$. These extrinsic facts about the world do not, prima facie, seem to be the kind of facts that should determine the facts about phenomenology at $t$. Second, the view entails that although there are truthmakers located in the past for claims such as "Caesar crossed the Rubicon," other claims such as "Caesar was nervous as he crossed the Rubicon" are not made true by the existence of objects in the past, since there is no object in the past that is nervous. The growing-block theorist must offer a different account of what grounds the truth of past-tensed claims that attribute phenomenological states to individuals than what grounds the truth of all other past-tensed claims (Heathwood 2005). 


\section{Where to from Here?}

It is fair to say that all three views about the nature of time and ontology face challenges. Which view one finds conducive will depend in large part on one's intuitions about the various costs and benefits of each view. I do not want to try and offer an overall cost-benefit analysis. Instead, it is profitable to think about the key challenges that each view faces, and some avenues of future investigation.

For the eternalist, the key challenge lies in explaining temporal phenomenology and in explaining the apparent directionality of time. There has been significant work in this area, but questions still remain: why do we have such a different relationship with the future than with the past: why is it that effects typically precede their causes when the laws of nature are symmetric: why do we remember the past, but not the future: why does the present seem to us to have a particularly salient quality that other moments lack; what are the cognitive apparatuses that underlie our experience of temporality and how do they function to create temporal phenomenology; what is the evolutionary significance of the phenomenology of temporal flow and to what extent is the phenomenology of temporal flow essential for agency. Presentism and the growing block theory have easy answers to some of these questions, but eternalism owes us more by way of an account of these phenomena. This is where the real work lies. If the eternalist can present a sufficiently robust, nuanced and plausible story about how we come to have the phenomenology we do, what role that phenomenology plays, and what features of the world that phenomenology tracks, given that it does not track temporal flow, then this will render eternalism very difficult to beat as the correct account of the ontology and temporal structure of our world.

The key challenge for both growing-blockism and presentism is, as I see it, resolving objections in a way that does not undermine the very motivation for accepting either of these views. Both views are motivated by the thought that prima facie, and in the absence of contravening evidence, the way the world seems to us is a good guide to the way the world is. Sometimes the way the world seems to us to be is not the way that it is. Such discoveries, such as the empirical discoveries that underlie STR, present problems for presentism and growing-blockism. The issue they face is not that their views cannot be made consistent with STR, but rather, that the most naturalistically and scientifically respectable ways of doing so radically undermines the motivations for either view. For in making the privileged present empirically undetectable, it becomes very difficult to see how the presence of such a present could be the explanation for our temporal phenomenology, the very thing that motivates both views to posit a privileged present in the first place.

The form of this problem generalizes. In the case of growing-blockism it rears its head in the guise of the various responses the growing-blockist mounts to the epistemic objection. The growing-blockist must either say that only objectively present persons have phenomenology, thus presenting a radically new view of what it takes for an arrangement of matter at a time to form the supervenience base for consciousness, or she must concede that we cannot know that we are in the objective present. The former is, arguably, independently implausible. The latter radically undermines the growingblock theorist's motivations for her view, since it implies that we have the same phe- 
nomenology as of temporal passage and of being in the present, regardless of whether we are in the objective present, or in the objective past where there is no passage.

Presentism is viable only if it can provide a plausible account of the truthmakers for past and perhaps also future-tensed statements. But the more plausible the account is, by which I mean, the more the truthmakers for past-tensed statements are like the truthmakers for present-tensed statements, the less presentism is obviously distinct from eternalism. On the other hand, the less they are like the truthmakers offered by the eternalist, the less plausible they are as truthmakers for past-tensed claims. It is a core claim of presentism that certain events did occur. If the presentist cannot adequately account for past-tensed claims, it is difficult to see how she could vindicate the dynamical thesis of presentism, since that requires that there were past times that did exist.

Finally, one last issue that has received much less attention than it ought is whether whichever of these views is actually true is also necessarily true. I do not have the space to explore this issue, so I leave it as a task to the reader to think about where in modal space she supposes these views to be located.

\section{Notes}

1 I assume that Santa Claus is not an abstract object.

2 While "exists" is often understood in terms of quantification over domains, not everyone supposes that this is the right way to understand existence. Meinongians, for instance, think that one can quantify over things that do not exist, since they suppose that existence is a property that bundles of properties can have, or lack. For a discussion of this view see Parsons (1995), Parsons (1974) and Rapaport (1978).

3 For a nuanced discussion of the various ways to define presentism see McKinnon (2011).

4 It is worth noting that it is, or need be, no part of eternalism that these relations are absolute or frame-invariant. Absolute simultaneity is discussed in Section 3.1

5 More precisely, it is consistent with eternalism that a world be composed of a single time-slice, and hence that in such a world past, present and future moments do not exist. Only a single moment exists. But such a world is not a presentist world, since which moment exists does not change. It is better, therefore, to think of the eternalist's claim about the existence of the past, present and future, as conditional claims: if a world has a temporal dimension, then past, present and future moments and events exist. For further discussion of the definition of eternalism see Baron and Miller (2011).

6 An exception is Hinchliff (2000), who considers two kinds of presentism: point presentism, where only a single point is present, and cone presentism, where the present for $E$ is defined as the surface of E's backwards light cone. Both views require that there is a privileged present, but not a privileged foliation.

7 There are some notable dissenters to this view. For instance see Barnes and Cameron (2009).

8 Of course, the growing-block theorist could invoke future-tensed properties (or an analogous strategy) to ground future-tensed claims if they wanted to adopt a closed future, the point is just that they have a natural way to understand the fixity of the past and openness of the future given their model.

9 These objections apply to any dynamical view with an ontology that includes more than just the present moment - and thus include the moving spotlight view and the shrinking branches view. 


\section{References}

Barnes, E. and Cameron, R. (2009). The Open Future: Bivalence, Determinism and Ontology. Philosophical Studies 146, 291-309.

Baron, S. and Miller, K. (2011). Defining Eternalism. In Robert Ciuni, Kristie Miller and Giuliano Torreng (eds.). New Papers On The Present - Focus On Presentism. Munich: Philosophia Verlag.

Bigelow, John. (1996). Presentism and properties. In Metaphysics, vol. 10 James Tomberlin (ed.). Philosophical Perspectives (35-52). Oxford: Blackwell.

Bourne, C. (2002). When Am I? A Tense Time for Some Tense Theorists? Australasian Journal of Philosophy 80(3), 359-71.

Bourne, C. (2006). A Future for Presentism. Oxford: Clarendon Press.

Braddon-Mitchell, D. (2004). How Do We Know It Is Now Now? Analysis 64(3), 199-203.

Button, T. (2006). There's No Time Like the Present. Analysis, 66(290), 130-35.

Button, T. (2007). Every Now and Then, No-Futurism Faces No Sceptical Problems. Analysis 67(296), 325-32.

Caplan, B. and Sanson, D. (2011). Presentism and Truthmaking. Philosophy Compass 6(3), 196-208.

Craig, W.L. (2000). The Tensed Theory of Time: A Critical Examination. Dordrecht: Kluwer Academic Publishers.

Crisp, T.M. (2004). On Presentism and Triviality. In Dean W. Zimmerman (ed.). Oxford Studies in Metaphysics Vol. 1 (15-20). Oxford: Oxford University Press.

Crisp, T.M. (2005). Presentism and "Cross-Time" Relations. American Philosophical Quarterly $42(1), 5-17$.

Crisp, T.M. (2007). Presentism and the grounding objection. Noûs 41, 118-37.

Dyke, H. (2001). The Pervasive Paradox of Tense. Grazer Philosophische Studien 62(1), $103-124$.

Dyke, H. (2002a). Tokens, Dates and Tenseless Truth Conditions. Synthese 131(3), 329-51.

Dyke, H. (2002b). McTaggart and the Truth about Time. In Craig Callender (ed.). Time, Reality and Experience (137-153). Cambridge: Cambridge University Press.

Forrest, P. (2004). The Real but Dead Past: A Reply to Braddon-Mitchell. Analysis 64(4), $358-62$.

Forrest, P. (2006). Uniform Grounding of Truth and the Growing Block Theory: A Reply to Heathwood. Analysis, 66(290), 161-63.

Heathwood, C. (2005). The Real Price of the Dead Past: A Reply to Forrest and to BraddonMitchell. Analysis 65(287), 249-51.

Hinchliff, M. (2000). A Defense of Presentism in a Relativistic Setting. Philosophy of Science 67, Supplement. Proceedings of the 1998 Biennial Meetings of the Philosophy of Science Association. Part II: Symposia Papers, 575-86.

Hirsch, E. (2002). Quantifier Variance and Realism. Philosophical Issues 12 Realism and Relativism, 51-73.

Keller, S. (2004). Presentism and Truthmaking. In Dean W. Zimmerman (ed.). Oxford Studies in Metaphysics Vol. 1 (83-104). Oxford: Oxford University Press

Kierland, B. (2011). Grounding Past Truths: Overcoming the Challenge. In Robert Ciuni, Kristie Miller and Giuliano Torreng (eds.). New Papers On The Present - Focus On Presentism. Munich: Philosophia Verlag.

Le Poidevin, Robin (1991). Change, Cause and Contradiction: A Defence of the Tenseless Theory of Time. New York: St. Martin's Press.

Lewis, D. (2004). Tensed Quantifiers. In Oxford Studies in Metaphysics, edited by Dean Zimmerman, 3-15. Oxford: Oxford University Press. 
Lowe, E.J. (1992). McTaggart's Paradox Revisited. Mind 101 (402), 323-326.

Lowe, E.J. (2011). Presentism and Relativity. In Robert Ciuni, Kristie Miller and Giuliano Torreng (eds.). New Papers On The Present - Focus On Presentism. Munich: Philosophia Verlag.

Ludlow. P. (1999). Semantics, Tense, and Time. Cambridge, MA: MIT Press.

Ludlow, P. (2004). Presentism, Triviality, and the Varieties of Tensism. In Dean W. Zimmerman (ed.). Oxford Studies in Metaphysics Vol. 1 (21-36). Oxford: Oxford University Press.

Markosian, N. (2004). A Defense of Presentism. In Dean W. Zimmerman (ed.). Oxford Studies in Metaphysics Vol. 1 (47-82). Oxford: Oxford University Press.

McKinnon, N. (2011). Characterising Presentism. In Robert Ciuni, Kristie Miller and Giuliano Torreng (eds.). New Papers On The Present - Focus On Presentism. Munich: Philosophia Verlag.

McTaggart, J.M.E. (1908). The Unreality of Time. Mind, 17, 456-73.

Mellor, D.H. (1981). Real Time. Cambridge: Cambridge University Press.

Mellor, H. (1998). Real Time 2. London: Routledge.

Meyer, U. (2005). The Presentist's Dilemma. Philosophical Studies 122, 213-25.

Meyer, U. (2011). The Triviality of Presentism. In Robert Ciuni, Kristie Miller and Giuliano Torreng (eds.). New Papers On The Present - Focus On Presentism. Munich: Philosophia Verlag.

Merricks, T. (2006). Good-Bye Growing Block. In Dean W. Zimmerman (ed.). Oxford Studies in Metaphysics Vol. 1 (103-11). Oxford: Oxford University Press.

Minkowski, H. (1908). Space and Time. In H.A Lorentz, A. Einstein , H. Minkowski and H. Wehl The Principle of Relativity (73-91). New York: Dover (1952).

Oaklander, L. Nathan (2002). Presentism, Ontology and Temporal Experience. Royal Institute of Philosophy Supplement (50), 73-90.

Parsons, T. (1974). A Prolegomenon to Meinongian Semantics. The Journal of Philosophy, 71(16), 561-80.

Parsons, T. (1995). Meinongian Semantics Generalized. Grazer Philosophische Studien 50, 145-62.

Peterson, D. and Silberstein, M. (2010). Relativity of Simultaneity and Eternalism: In Defense of the Block Universe. In Vesselin Petko (ed.). Space, Time and Space-time: Fundamental Theories of Physics. Volume 167, part 2, 209-237. Berlin: Springer.

Price, H. (1997). Time's Arrow and Archimedes' Point: New Directions for the Physics of Time. Oxford: Oxford University Press.

Prior, A.N. (1967). Past, Present, and Future. Oxford: Clarendon Press.

Prosser, S. (2000). A New Problem for the A-Theory of Time. The Philosophical Quarterly 50(201), 494-98.

Prosser, S. (2007). Could We Experience the Passage of Time? Ratio 20(1), 75-90.

Putnam, H. (1967). Time and Physical Geometry. Journal of Philosophy 64, 240-247.

Quine, W.V.O. (1960). Word and Object. Cambridge, MA: MIT Press.

Quine, W.V.O. (1963). Identity, Ostention and Hypostasis. In From a Logical Point of View. (65-79). New York: Harper and Row.

Rapaport, W. (1978). Meinongian Theories and a Russelian Paradox. Noûs 12(2), 153-80.

Savitt, S. F. (2000). There's No Time Like the Present (in Minkowski Spacetime). Philosophy of Science, 67, Supplement. Proceedings of the 1998 Biennial Meetings of the Philosophy of Science Association. Part II: Symposia Papers, 563-74.

Sider, T. (1999). Presentism and Ontological Commitment. Journal of Philosophy 96, 325-47.

Sider, T. (2006). Quantifiers and Temporal Ontology. Mind 115, 75-97.

Skow, B. (2009). Relativity and the Moving Spotlight. Journal of Philosophy 106(12), 666-678.

Smart, J.J.C. (1968). Between Philosophy and Science: An Introduction to the Philosophy of Science. New York: Random House.

Smith, Q., and Oaklander, L. N., (eds.) (1994). The New Theory of Time. New Haven, CT: Yale University Press. 


\section{KRISTIE MILLER}

Tallant, J. (2009). Presentism and Truth-Making. Erkenntnis 71, 407-16.

Thomson, J.J. (2001). McTaggart on Time. Noûs 35(s15), 299-252.

Tooley, M. (1997). Time, Tense and Causation. Oxford: Clarendon Press.

Wüthrich, C. (2011). The Fate of Presentism in Modern Physics. In Robert Ciuni, Kristie Miller and Giuliano Torreng (eds.). New Papers On The Present - Focus On Presentism. Munich: Philosophia Verlag.

Zimmerman, D. (2008). The Privileged Present: Defending an 'A-theory' of Time. In Theodore Sider, John Hawthorne, and Dean Zimmerman (eds.). Contemporary Debates in Metaphysics (211-225). Oxford: Blackwell. 